
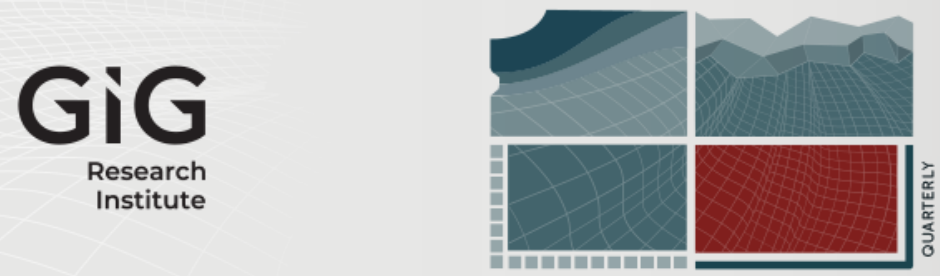

JOURNAL

OF

SUSTAINABLE

MINING

\title{
Optimum location of last-mined stope with the influence of backfilling
}

Author(s) ORCID Identifier:

Derek B. Apel (iD) 0000-0002-5402-7036

Huawei Xu (iD 0000-0002-1123-2080

Follow this and additional works at: https://jsm.gig.eu/journal-of-sustainable-mining

Part of the Geological Engineering Commons, and the Mining Engineering Commons

\section{Recommended Citation}

Xu, Huawei and Apel, Derek B. (2020) "Optimum location of last-mined stope with the influence of backfilling," Journal of Sustainable Mining: Vol. 19 : Iss. 4 , Article 1.

Available at: https://doi.org/10.46873/2300-3960.1022

This Research Article is brought to you for free and open access by Journal of Sustainable Mining. It has been accepted for inclusion in Journal of Sustainable Mining by an authorized editor of Journal of Sustainable Mining. 


\title{
Optimum location of last-mined stope with the influence of backfilling
}

\begin{abstract}
Many mines in Canada have adopted sublevel stoping method or one of its variations, such as blasthole stoping (BHS) and sublevel longhole retreat (SLR), for the extraction of steeply dipping orebodies. Stope, as the basic excavated element, plays a significant role in the whole process of mining activity. In the mining method of BHS, crossing cuts are excavated at tops and bottoms in each stope for drilling blast holes and transportation of mined out orebodies. Crossing cuts failure may result in prolonged production interruption, fatality, and equipment loss. After the completion of orebodies excavation from the sublevel open stope, the void stopes will be backfilled with cemented rockfill (CRF) for secondary stopes. The strength of the CRF affects the stability of the adjacent crossing cuts for the next excavation scheme. Rational location of the last mined stope can effectively eliminate the instability of crossing cuts. By using the Finite Element Method (FEM), this paper presents the comparison of floor heaves, roof displacements, and sidewall swellings of the crossing cuts in each stopes of different location scenarios. The numerical simulation shows that the central stope location of the level is the optimum one for the last mined stope.
\end{abstract}

\section{Keywords}

Backfill, sublevel stoping method, numerical modelling

Creative Commons License (c) (i) (9)

This work is licensed under a Creative Commons Attribution-Noncommercial-No Derivative Works 4.0 License.

\section{Cover Page Footnote}

The financial support for this research was provided by Natural Sciences and Engineering Research Council of Canada. 


\title{
Optimum location of last-mined stope with the influence of backfilling
}

\author{
Huawei Xu, Derek B. Apel* \\ Department of Civil and Environmental Engineering, University of Alberta, Edmonton, Alberta, Canada
}

\begin{abstract}
Many mines in Canada have adopted sublevel stoping method or one of its variations, such as blasthole stoping (BHS) and sublevel longhole retreat (SLR), for the extraction of steeply dipping orebodies. Stope, as the basic excavated element, plays a significant role in the whole process of mining activity. In the mining method of BHS, crossing cuts are excavated at tops and bottoms in each stope for drilling blast holes and transportation of mined out orebodies. Crossing cuts failure may result in prolonged production interruption, fatality, and equipment loss. After the completion of orebodies excavation from the sublevel open stope, the void stopes will be backfilled with cemented rockfill (CRF) for secondary stopes. The strength of the CRF affects the stability of the adjacent crossing cuts for the next excavation scheme. Rational location of the last mined stope can effectively eliminate the instability of crossing cuts. By using the Finite Element Method (FEM) such as Abaqus codes in this study, this paper presents the comparison of floor heaves, roof displacements, and sidewall swellings of the crossing cuts in each stopes of different location scenarios. The numerical simulation shows that the central stope location of the level is the optimum one for the last mined stope.
\end{abstract}

Keywords: backfill, sublevel stoping method, numerical modelling

\section{Introduction}

$S$ topes, as the basic excavation element of sublevel open stoping mining method in underground mining, play key role in the whole production process. Mathews [1] initially proposed stability graph to predict the open-stope stability, and this method based on a limited number of cases. Chen [2] showed that the stope height was the critical design parameter. Bai [3] presented a new algorithm to optimize stope design for the sublevel stoping mining method with two parameters: (i) the maximum distance of a block from the raise and (ii) the horizontal width required to bring the farthest block to the raise. Cai [4] assumed tensile cracking as the dominant fracture mechanism for brittle rocks under compressive pressure. Diederichs [5] explored the influence of residual tensile strength and boundary parallel relaxation on the failure process by using crack and rock-bridge analogues, and updated the empirical stability assessment techniques for underground tunnels and for mining stopes. Martin [6] provided examples to illustrate how the philosophy of observational design method can be used to infer the in situ stress state. Zhang [7] presented that previous beneath mining activities significantly affected the stability of stope walls by the method based on yield zone distribution. Cepuritis [8] back-analyzed hanging wall over-break data from longhole open stopes, and established global relationships between velocity and plastic strain and marked increases in over-break. Idris [9-11] studied the stability of open stopes considering the variability in the rock mass properties and divided rock mass into six strength classes. Cai [12] presented a systematic assessment of uncertainty in rock mass characterization in rock engineering. Kurlenya [13] presented the estimation of stability of stopes in

Received 9 October 2020; revised 11 November 2020; accepted 12 November 2020.

Available online 07 December 2020

* Corresponding author.

E-mail address: derek.apel@ualberta.ca (D.B. Apel). 
the bottom-up slice mining by modelling the stress-strain state and in situ observations. Urli [14] presented the ore-skin design approach, and showed that the minimum ore-skin thickness required depends on the quality of governed rock mass and could be a function of stope lifetime. Heidarzadeh [15] evaluated the individual and interactive effects of open stope geometrical parameters related to brittle damage of the surrounding rock mass. (see Table 1 )

For stope stability assessment, many works were done on displacement prediction, mining induced stress assessment, protect supporting design. While the location optimization of the last-mined stope was rarely discussed, especially with the influence of the CRF backfilling mining method. The location of the last-mined stope plays a key role in mining safety and resource recovery rate in each level. Rational location of the last-mined stope can not only improve the resource recovery rate but also with lower instability of overcuts and undercuts. In this paper, the influence of the CRF backfilling is considered to optimize the location of the last mined stope.

\section{Materials and methods}

BHS mining method includes two sublevels and amount of preparation of the stopes before production commence. One sublevel is on the top of the stope, it is for drilling (overcut), and another is at the bottom of the stope, it is for production (undercut). Hustrulid [16] classified the features of the mines which apply BHS mining method, and the features are: i) host rock and orebody are competent, ii) orebody dip is steep, iii) boundaries of orebody are regular. For most of the hard rock mines in Canada, the orebody blocks are usually steeply inclined. The mine chosen as the case in this paper has the above features.

\subsection{Numerical modelling establishment}

Referring to the works of Jing [17, 18], Hart [19], Wiles [20] and Cai [21], the numerical analysis can assist in simulation of forced conditions on the rock mass and its response behaviors; this brings the advantage of predicting possible failures by identifying the observed mechanisms that governs failure in similar conditions. Numerical modeling plays a great role in the design and assessment of the rock mass behavior. FEM is perhaps the most widely applied numerical method in engineering today because of its flexibility in handling material heterogeneity, non-linearity and complicated boundary conditions and dynamic problems, with many well developed and verified commercial codes with large capacities in terms of computing power, material complexity and user-friendliness, Sun [22].

In this study, the hard rock mine transferred from open pit mining to underground mining. There are two open pits, namely Op1 and Op2. Under Op2, there are two orebody zones, namely Ore-zone-1 and Ore-zone-2. In order to better simulate the mining process, despite the focus is the Op2, the Op1 is also included in the model to capture the possible impacts of its geometry on the mininginduced stress field. This makes the model domain: $2200 \times 2200 \times 800 \mathrm{~m}$ (length $\times$ width $\times$ depth). This size of domain eliminates the influence of boundaries on the model.

The analysis of mining induced stress field in this paper is global to local, firstly a full size 3D numerical model was created, and then the stress filed of the researched level is extracted and applied to the simplified 2D model. In the full size 3D numerical model, the ten-node quadratic tetrahedron mesh element (C3D10) [23]was used to conduct the simulation and achieve better results of the mininginduced redistributed stress. For the simplified 2D model, the four-node bilinear plane quadrilateral mesh element (CPE4R) [23] was used. Since the acceptable constitutive model failure criteria in Abaqus for rock is the Mohr-Coulomb failure criteria [23], then both the 2D and 3D models use the Mohr-Coulomb failure criteria for the simulation calculation. The researched zone in this paper locates in Ore-zone-2. As shown in Fig. 1, there are seven levels and one sill pillar in Ore-zone-2. The heights of the stope in each level are the same, and it is $25 \mathrm{~m}$, and the width is $7 \mathrm{~m}$. Also, the height of the sill pillar is $20 \mathrm{~m}$. As for the overcuts and undercuts

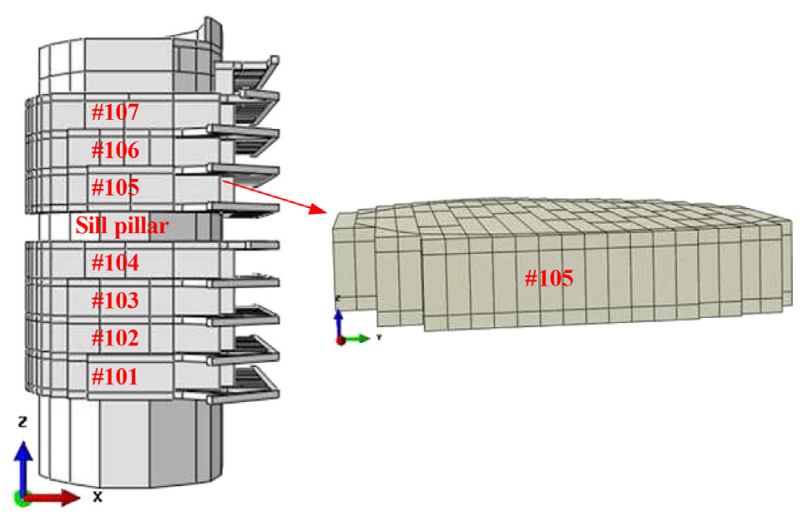

Fig. 1. Modelled Ore-zone-2 and modelled level. 
Table 1. Material properties.

\begin{tabular}{llllllll}
\hline Rock Mass & $\gamma\left(\mathrm{MN} / \mathrm{m}^{3}\right)$ & $\mathrm{C}(\mathrm{MPa})$ & $\phi\left(^{\circ}\right)$ & $\mathrm{E}(\mathrm{GPa})$ & $v$ & $\sigma \mathrm{t}(\mathrm{MPa})$ & $\sigma \mathrm{c}(\mathrm{MPa})$ \\
\hline Ore Zone 1 & 0.024 & 4.2 & 26.4 & 18.7 & 0.26 & 3.4 & 3.7 \\
Ore Zone 2 & 0.024 & 4.7 & 28.1 & 19.6 & 0.24 & 0 & 79 \\
Backfilling CRF & 0.022 & 1.2 & 35 & 2 & 0.3 & 0 & 1.5 \\
Granite & 0.026 & 9.3 & 45 & 24 & 0.3 & 0 & 130 \\
\hline
\end{tabular}

in each level, the height is $5 \mathrm{~m}$ and the width is same with the width of stope. One mining level, \#105, is selected to study the topic. There are twenty one stopes in level \#105. Fig. 1 shows the outline of Orezone-2 and level \#105.

\subsection{Mechanics properties of modelled rock and backfilling CRF}

Table 1 shows the material properties used in the model [24]. Here, $\gamma$ is the unit weight, $C$ is the cohesive strength, $\phi$ is the angle of friction, $E$ is the elastic Young's modulus, $v$ is the Poisson's ratio, $\sigma_{t}$ is the tensile strength and $\sigma_{\mathrm{c}}$ is the maximum uniaxial compressive strength.

The following Fig. 2, Fig. 3 and Fig. 4 show the two dimensional numerical model of the level
\#105. The 2D model has a size of $100 \times 147 \mathrm{~m}$ (height $\times$ width). Dark green represents the kimberlite orebody, and the white is the backfilled CRF. Above the level \#105, it is $25 \mathrm{~m}$ thick kimberlite orebody, and below the level \#105 it is $50 \mathrm{~m}$ thick kimberlite orebody.

Following Fig. 2 shows three representative locations of the last mined stope in the level. Location 1 means that the last mined stope is at the very right side of the level. Location 21 means the last mined stope is at the very left side of the level. During the simulation process, the location of the last mined stope changes the location from location 1 to location 21. Location 11 means that the last mined stope is in the middle of the level. The void area in the figure is the overcut.
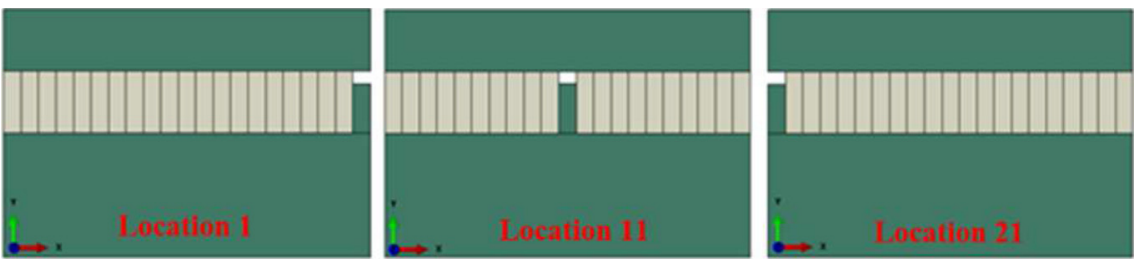

Fig. 2. Representative location with overcut of Scenario 1 (S1).
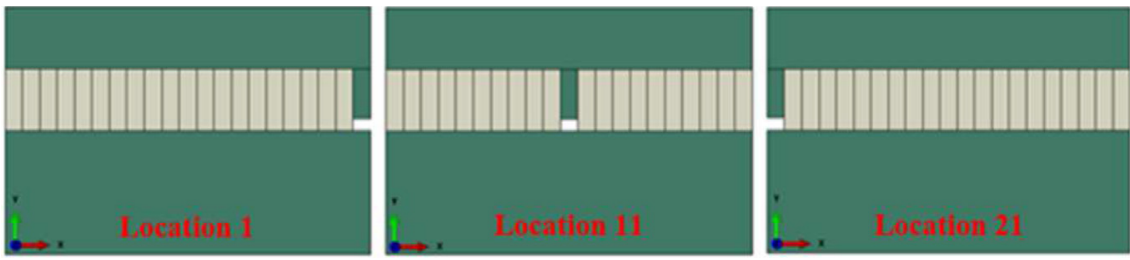

Fig. 3. Representative location with undercut of Scenario 2 (S2).
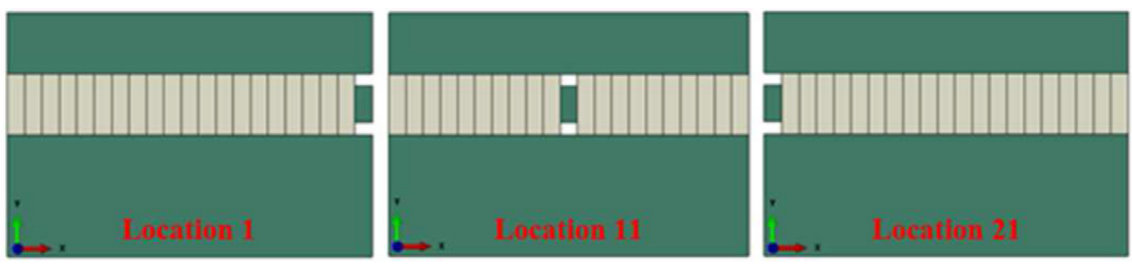

Fig. 4. Representative location with overcut and undercut of Scenario 3 (S3). 


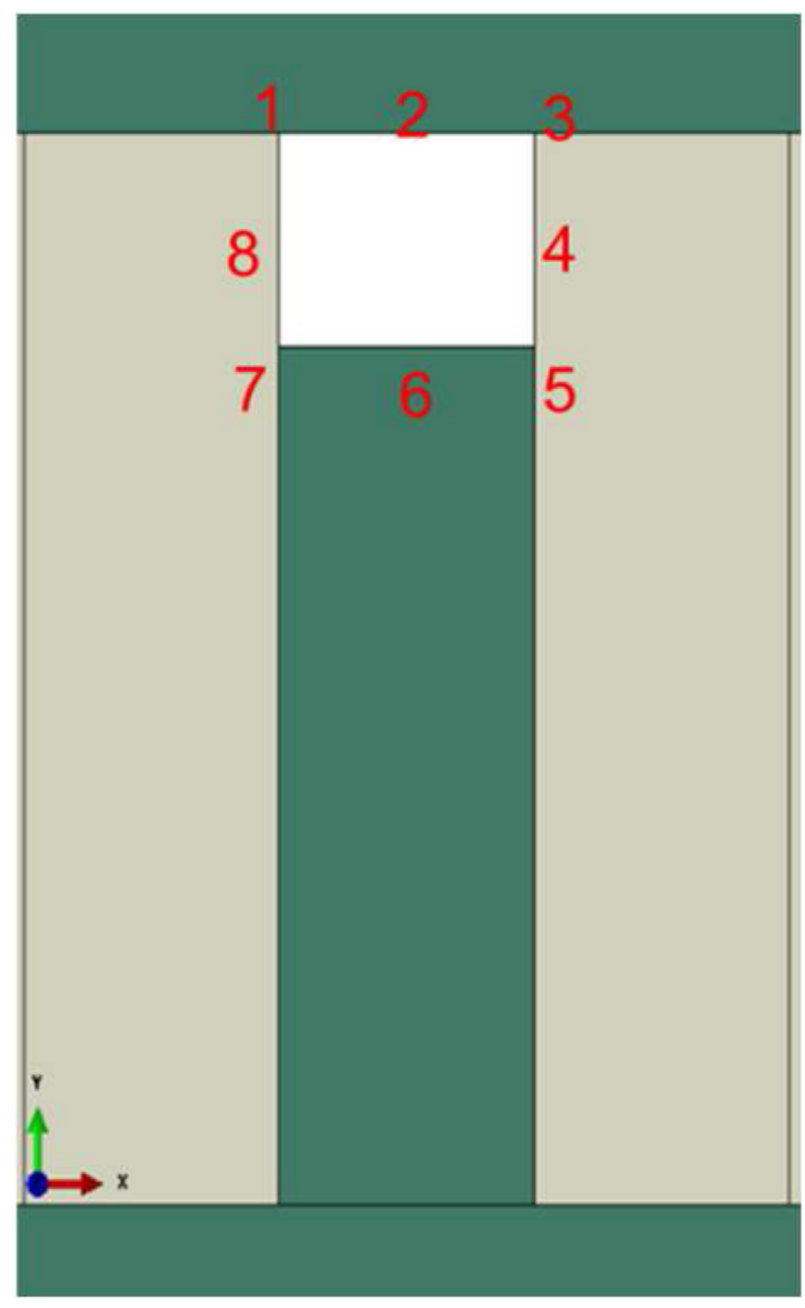

Fig. 5. Chosen comparison location in overcut.

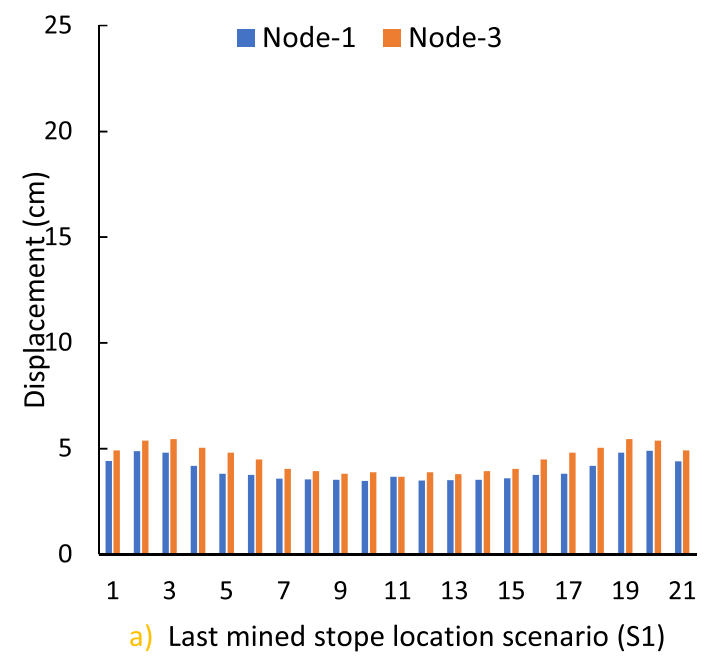

Fig. 3 presents the locations of the undercut in each stope. The simulation process begins from the location 1 and ends at location 21 . The void area at the bottom of the stope is the undercut.

Fig. 4 shows the location of last mined stope with both overcut and undercut. S3 has the same simulation process with S1 and S2. All three scenarios have the same boundaries condition, also the same stress condition fields are applied to the three scenarios.

\section{Results and discussion}

From the overcut and undercut layout, eight locations are selected for the comparison. The node 1 and node 3 represent the roof corners of the overcut and undercut, node 2 and node 6 are the middle point of the roof and floor respectively. Node 4 and node 8 are the middle points of both sidewalls, and node 5 and node 7 are the floor corners, as shown in Fig. 5. Similarly, the locations chosen from the undercut also marked with eight nodes. The displacement of these eight locations are significant factors to indicate the safety of the crosscuts.

\subsection{Displacement of chosen location in overcut}

Fig. 6 shows the displacement of node 1 and node 3 of the overcut in both S1 and S3. In both scenarios, the displacement of the overcut corners is less than $5 \mathrm{~cm}$.

From Fig. 6, there is no significant difference among different location scenarios of the last mined stope. Each location of last mined stope has small and similar displacement even S3 has undercut at

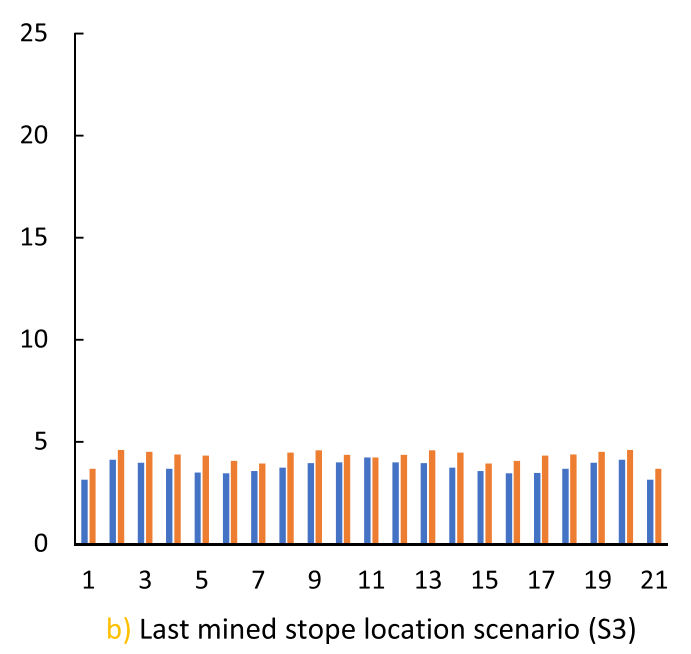

Fig. 6. Overcut displacement at Node-1, 3 of S1 and S3. 

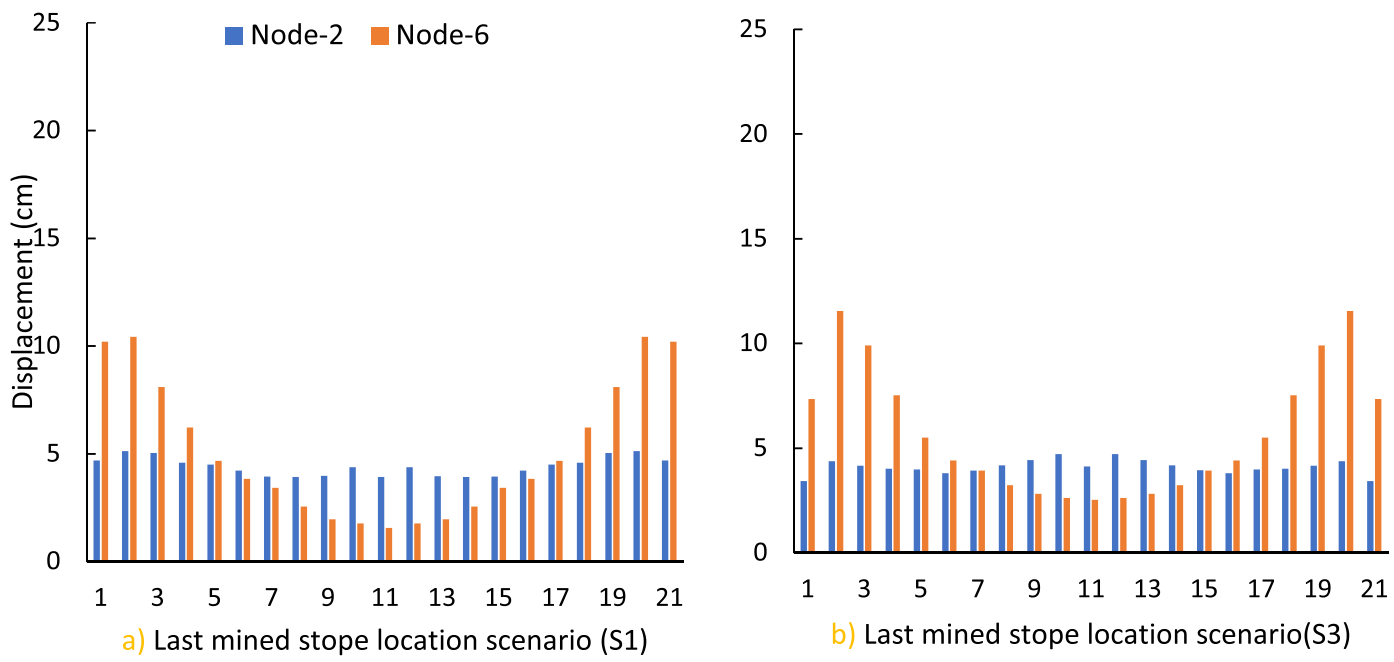

Fig. 7. Overcut displacement at Node-2, 6 of S1 and S3.

the bottom of the stope while S1 only has the overcut.

Fig. 7 presents the displacement of the middle point of roof and floor. In both scenarios, the displacement of the roof is small, as shown of the node 2. For the heave of the floor center, it is larger than the displacement of the roof center when the location of the last mined stope is away from the center axis of the level. Both the two corners and middle point of the roof has almost the same displacement. While for the locations around the center axis, the displacement of the roof center is larger than the heave of the floor center. For the heave of the floor, from each side to the center of the level, the displacement decreases gradually for both

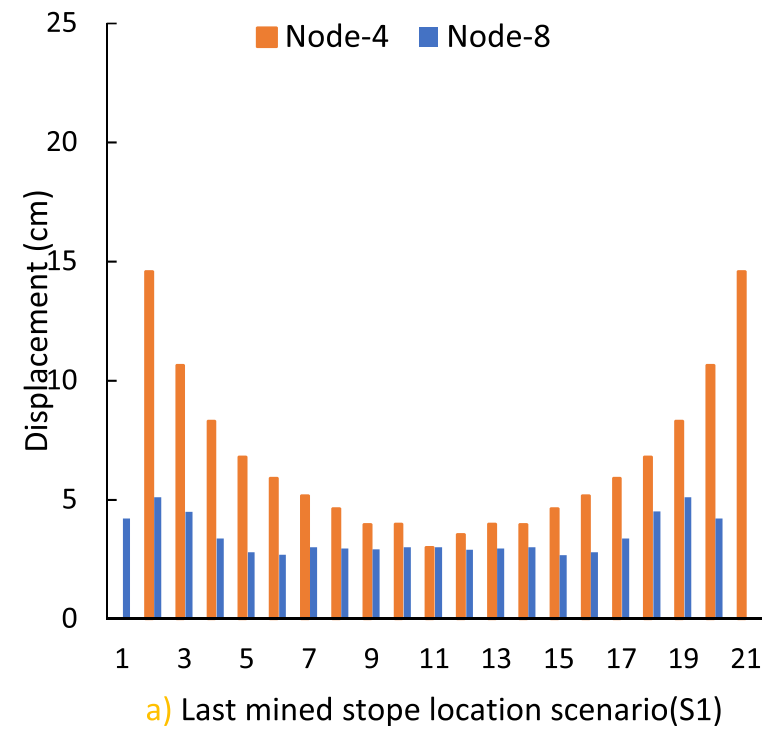

S1 and S3, and the floor center heave at the location 11 is the minimum one.

Fig. 8 shows the sidewall swellings. Similar with the change trend of roof displacement and floor heave, the central location of the level has the minimum sidewall swellings. At the same location of the last mined stope of S1 and S3, the swelling in S3 is larger than that in S1. While the swelling of the sidewall middle in S1 and S3 present different trend. In S1, the right sidewall has larger swellings, while in S3, the left sidewall has the larger swellings, which means the existence of undercut in S3 has influence on the sidewall swellings of overcut.

As shown in above Fig. 9, the heave of the two floor corners at the same location of the level is

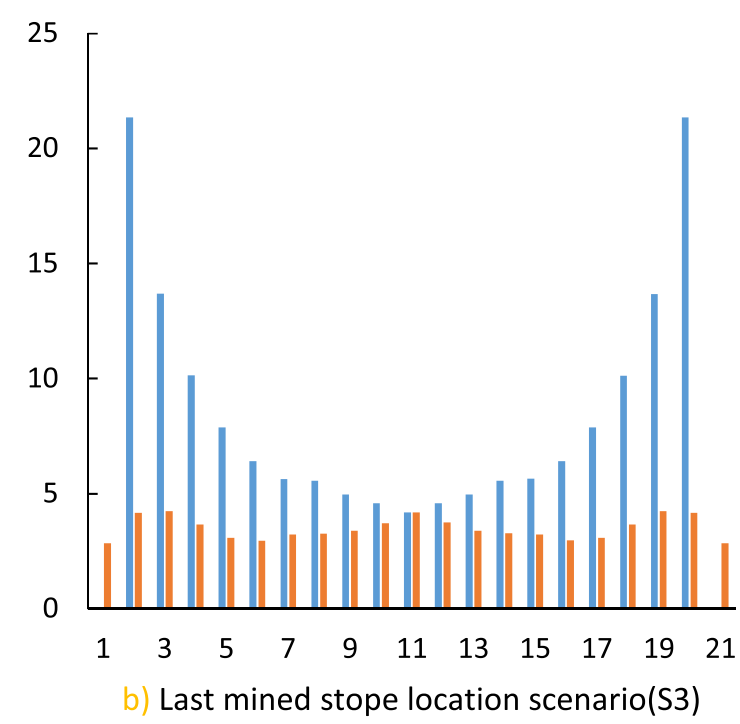

Fig. 8. Overcut displacement at Node-4, 8 of S1 and S3. 

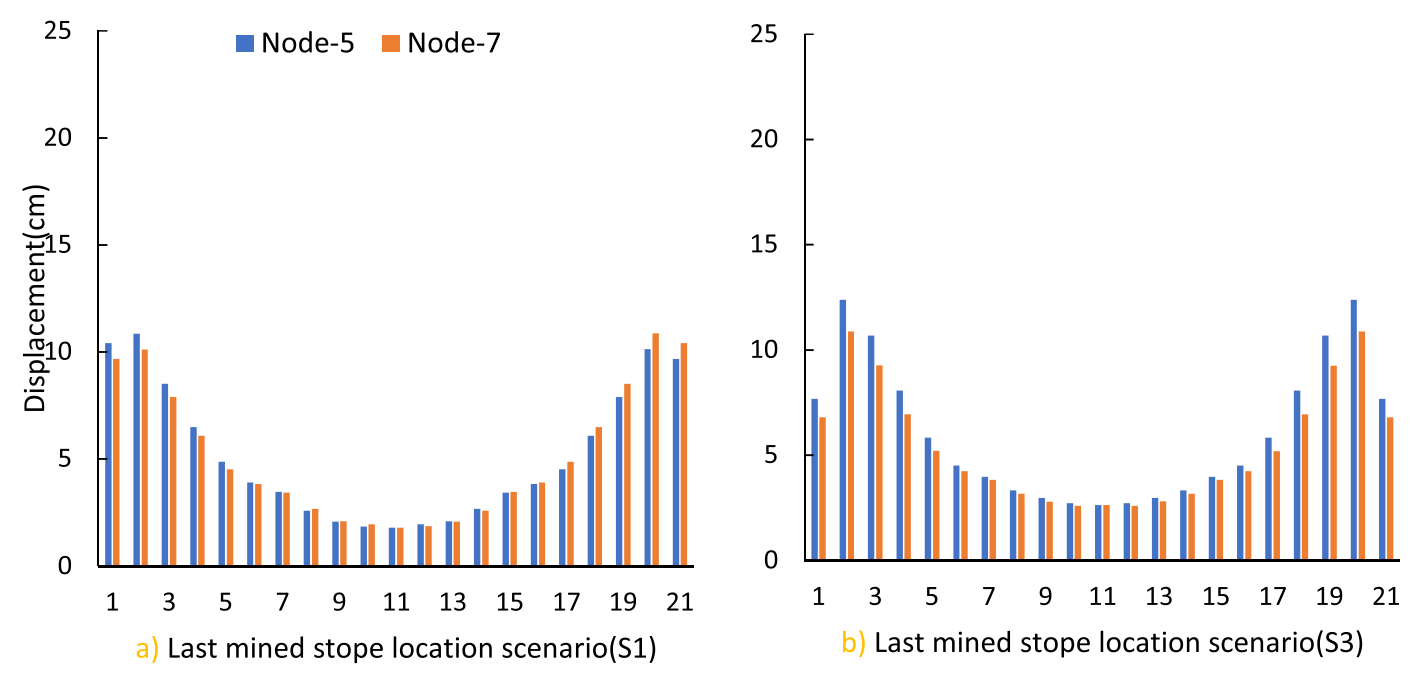

Fig. 9. Overcut displacement at Node-5, 7 of S1 and S3.

almost the same and most of them is less than $10 \mathrm{~cm}$. From the side to the center of the level the heave of the floor corners decrease gradually and the central location has the minimum value of the floor heave. The floor corners heave of the overcut in S3 is little bit large than that in S1 except the location at the very side boundaries.

\subsection{Displacement of chosen location in undercut}

Comparison of the displacement at node 1 and node 3 in the undercut in both S2 and S3 show the same trend. Different with the change trend in the overcut in S1 and S3, the displacement of node1 and node3 in undercut decreases from the side boundaries to the center of the level, as shown in Figs. 6 and 10. The displacement of the node1 and node 3 in the undercut is more sensitive to the influence of the backfilled CRF and the location of the last mined stope.

As shown in Fig. 11, for the displacement of node 2 and heave of node 6 in the undercut in S2 and S3, in both scenarios, the heave of node6 is tiny compared with the displacement of node2. The displacement of roof is more obvious than the heave of the floor in the undercut. Different with the change trend of the displacement of roof, the heave of the floor increases from the side boundaries to the central location of the level, even the floor heave is less than $3 \mathrm{~cm}$. Then the displacement of the roof
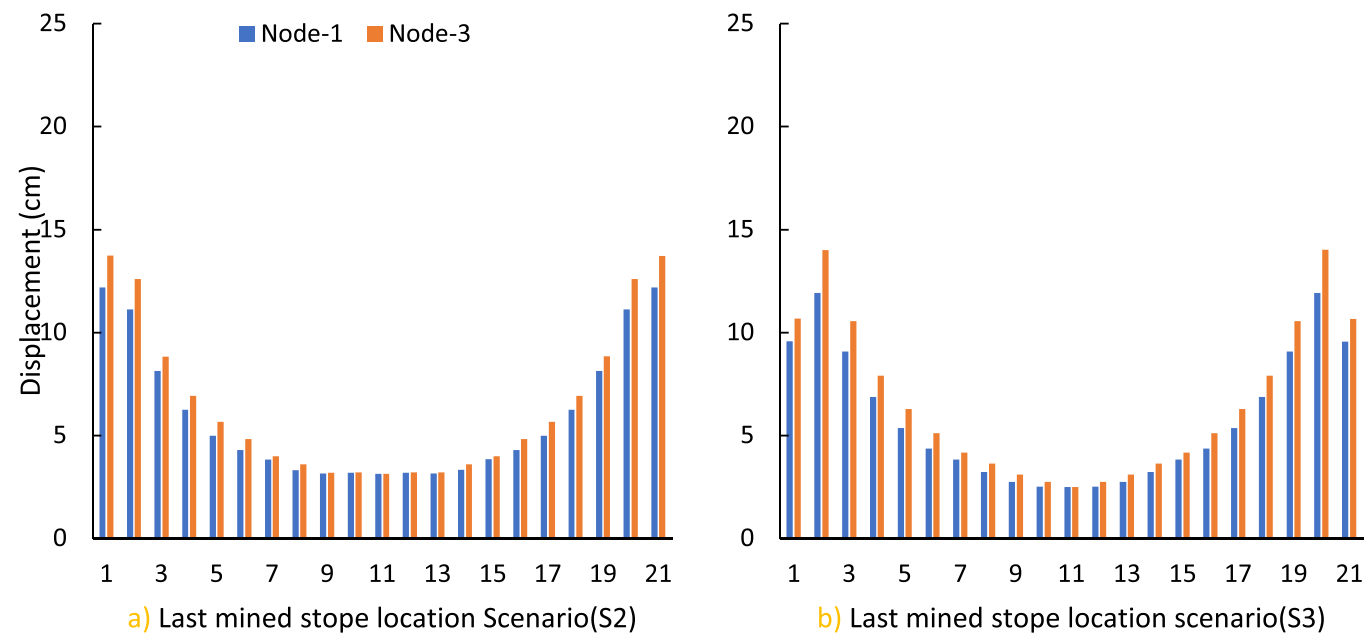

Fig. 10. Undercut displacement at Node-1, 3 of S2 and S3. 

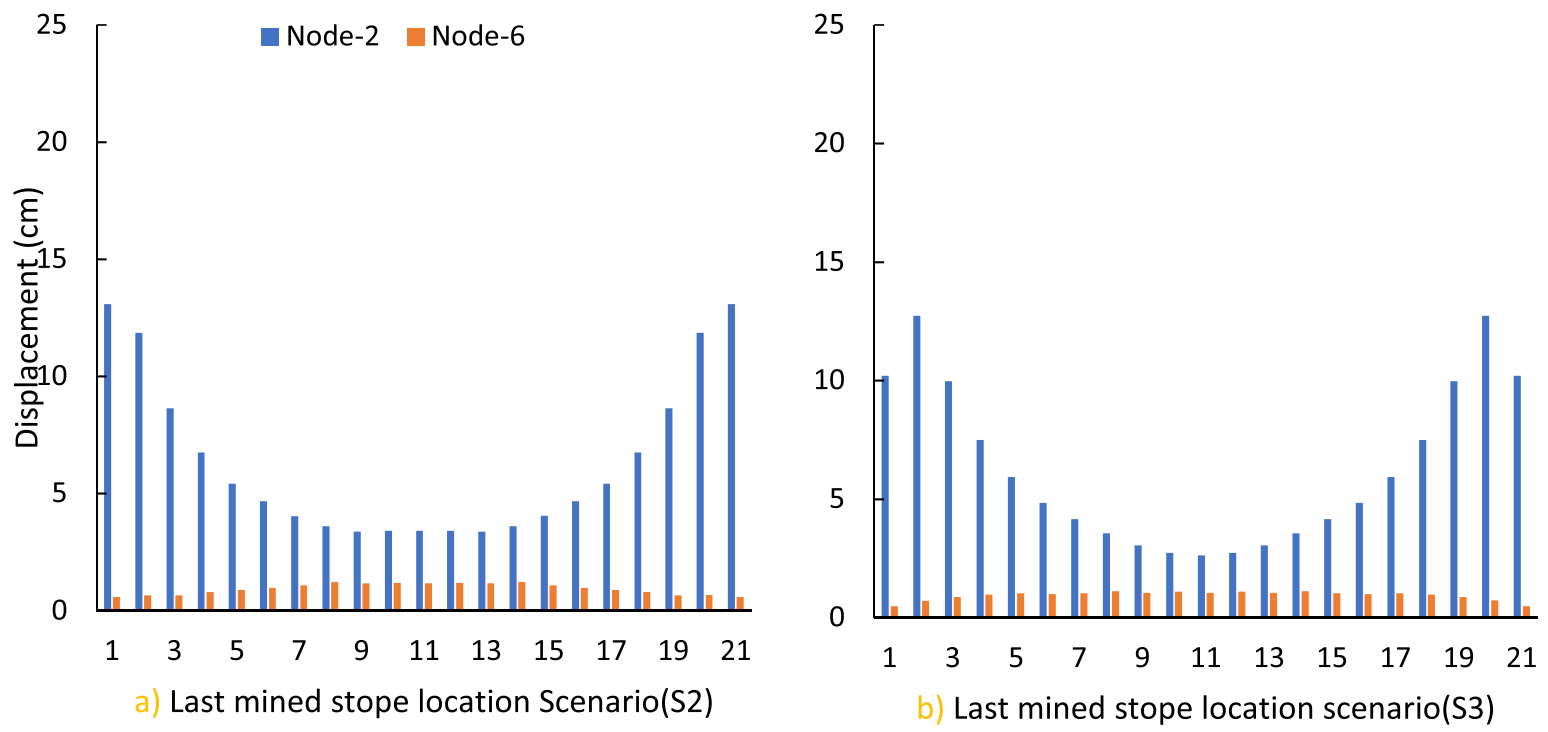

Fig. 11. Undercut displacement at Node-2, 6 of S2 and S3.
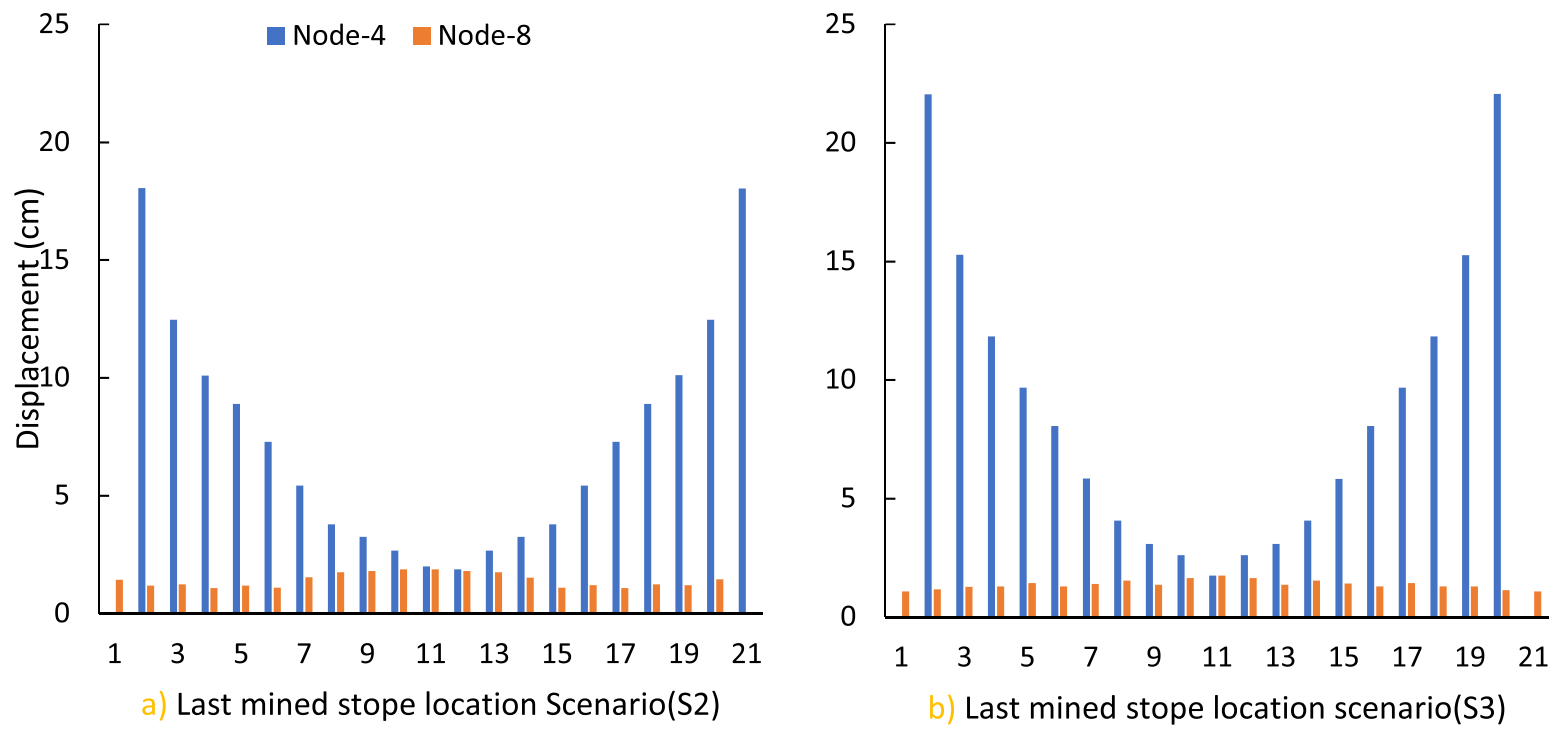

Fig. 12. Undercut displacement at Node-4, 8 of S2 and S3.

is an indication factor that more reliable than the heave of the floor in the undercuts.

Fig. 12 shows the sidewall swellings in the undercut of S2 and S3. Compared with the swellings of the right sidewall, the swellings of the left sidewall presents a different trend even the sidewall swellings is very small. According to Figs. 8 and 12, the sidewall swelling of the left sidewall in the overcut is larger than that of the undercut, while the change trend of the left sidewall swelling in undercut is sharper than that in the overcut.

For the floor corner heave, Fig. 13 shows that in the undercut in both S2 and S3. Different with the situations in the overcut shown in Fig. 9, the floor corner heave in the undercut is tiny, and there is no 

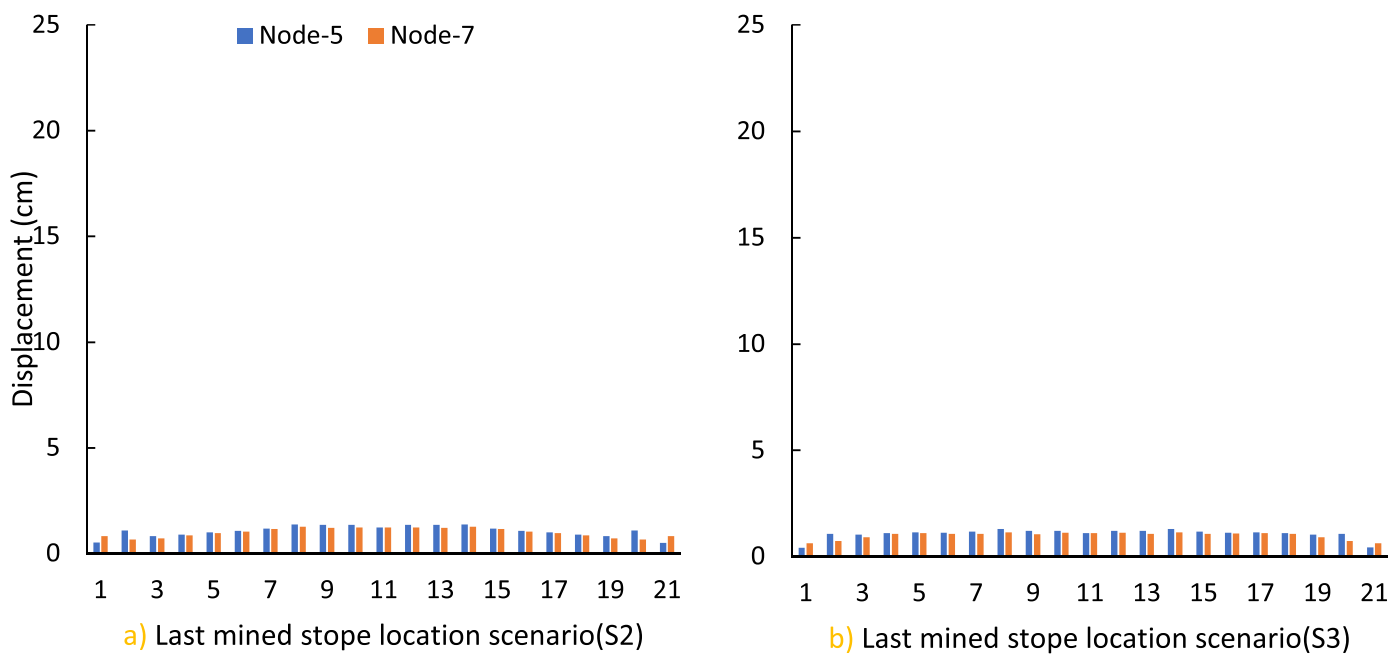

Fig. 13. Undercut displacement at Node-5, 7 of S2 and S3.

obvious difference among different location scenarios of the last mined stope.

\section{Conclusions}

Compared with undercut, the displacement of the roof corners in overcut is smaller, which means the roof in the overcut is more stable than that in undercut. As for the displacement of the roof middle in the overcut, there is no obvious difference in scenarios of S1 and S3, and the heave of the floor middle is larger than the displacement of the roof middle.

Different with the overcut, the floor middle heave in undercut is tiny, which means the floor in the undercut is more stable than the floor in overcut, as well the floor corners.

Due to the fact that the sidewalls in both undercuts and overcuts is the backfilled CRF and the strength of the CRF is lower than the kimberlite strength, then the supporting system of sidewalls should be stronger than that of the roofs in order to improve the safety of the working areas in both overcuts and undercuts.

In overcuts, more attention of supporting should be paid on the roof than on the floor. While in the undercuts, more attention should be paid on the floor than on the roof. Based on the above conclusions, the optimum location of the last mined stope is the central area of the level. In this case, the location scenario 10, 11 and 12 can be the location for the last-mined stope.

\section{Conflicts of interest}

None declared.

\section{Ethical statement}

Authors state that the research was conducted according to ethical standards.

\section{Funding body}

This research was funded by the Natural Sciences and Engineering Research Council of Canada (NSERC) under Collaborative Research and Development (CRD), grant number NSERC RGPIN-201904572.

\section{Acknowledgments}

This study was supported by the Natural Sciences and Engineering Research Council of Canada (NSERC) under Collaborative Research and Development (CRD) Grant (NSERC RGPIN-2019-04572). The supports from China Scholarship Council were acknowledged.

The supports from WestGrid and Compute/Calcul Canada were gratefully acknowledged.

\section{References}

[1] Mathews KE, Hoek E, Wyllie DC, Stewart S. Prediction of stable excavation spans for mining at depths below $1000 \mathrm{~m}$ in hard rock. Ottawa: CANMET DSS; 1981.

[2] Chen DW, Chen JY, Zavodni ZM. Stability analysis of sublevel open stopes at great depth. In: Proc 24th US Symp. Rock Mech., no. June; 1983. p. 587-97. https://doi.org/ 10.1016/0148-9062(84)91359-7.

[3] Bai X, Marcotte D, Simon R. Computers \& Geosciences Underground stope optimization with network flow method. Comput. Geosci. 2013;52:361-71. https://doi.org/10.1016/ j.cageo.2012.10.019.

[4] Cai M, Kaiser PK, Martin CD. "A Tensile Model for the Interpretation of Microseismic Events near Underground Openings," in Seismicity Caused by Mines. Fluid Injections, Reservoirs, and Oil Extraction 1998;153:67-92. 
[5] Diederichs MS, Kaiser PK. Tensile strength and abutment relaxation as failure control mechanisms in underground excavations. Int. J. Rock Mech. Min. Sci. 1999;36:69-96.

[6] Martin CD, Kaiser PK, Christiansson R. Stress , instability and design of underground excavationsvol. 40; 2003. p. 1027-47. https://doi.org/10.1016/S1365-1609(03)00110-2.

[7] Zhang Y, Mitri HS. Stability assessment of non-entry stopes using nonlinear finite element analysis [Online]. Available:. 2007. https://www.onepetro.org/conference-paper/ARMA07-165.

[8] Cepuritis PM, Villaescusa E, Beck DA, Varden R. Back analysis of Over-break in a Longhole Open Stope Operation using Non-linear Elasto-Plastic Numerical Modelling. 2010.

[9] Idris MA, Saiang D, Nordlund E. Consideration of the rock mass property variability in numerical modelling of open. In: in Bergmekanikdag; 2012. p. 111-23.

[10] Idris MA, Saiang D, Nordlund E. Numerical Analyses of the Effects of Rock Mass Property Variability on Open Stope Stability. 2011.

[11] Idris MA, Saiang D, Nordlund E. Probabilistic analysis of open stope stability using numerical modelling. Int. J. Min. Miner. Eng. 2011;3(3):194-219. https://doi.org/10.1504/ ijmme.2011.043849.

[12] Cai M. Rock Mass Characterization and Rock Property Variability Considerations for Tunnel and Cavern Design. Rock Mech. Rock Eng. 2011:379-99. https://doi.org/10.1007/ s00603-011-0138-5.

[13] V Kurlenya M, Baryshnikov VD, Gakhova LN. Experimental and Analytical Method for Assessing Stability of Stopes. J. Min. Sci. 2012;48(4):609-15. https://doi.org/10.1134/ s1062739148040028.

[14] Urli V, Esmaieli K. International Journal of Rock Mechanics \& Mining Sciences A stability-economic model for an open stope to prevent dilution using the ore-skin design. Int. J. Rock Mech. Min. Sci. 2016;82:71-82. https://doi.org/10.1016/ j.ijrmms.2015.12.001.
[15] Heidarzadeh S, Saeidi A, Rouleau A. Assessing the e ff ect of open stope geometry on rock mass brittle damage using a response surface methodology. Int. J. Rock Mech. Min. Sci. 2018;106:60-73. https://doi.org/10.1016/j.ijrmms.2018.03.015. March.

[16] Hustrulid WA, Hustrulid WA, Bullock RL, Bullock RC. Underground mining methods: Engineering fundamentals and international case studies. SME; 2001.

[17] Jing L, Hudson JA. Numerical methods in rock mechanics. Int. J. Rock Mech. Min. Sci. 2002;39(4):409-27. https:// doi.org/10.1016/S1365-1609(02)00065-5.

[18] Jing L. A review of techniques, advances and outstanding issues in numerical modelling for rock mechanics and rock engineering. Int. J. Rock Mech. Min. Sci. 2003;40(3):283-353. https://doi.org/10.1016/S1365-1609(03)00013-3.

[19] Hart R. Enhancing rock stress understanding through numerical analysis. Int. J. Rock Mech. Min. Sci. 2003;40(7-8): 1089-97. https://doi.org/10.1016/S1365-1609(03)00116-3.

[20] Wiles TD. Reliability of numerical modelling predictions. Int. J. Rock Mech. Min. Sci. 2006;43(3):454-72. https://doi.org/ 10.1016/j.ijrmms.2005.08.001.

[21] Cai M. Influence of stress path on tunnel excavation response - Numerical tool selection and modeling strategy. Tunn. Undergr. Sp. Technol. 2008;23(6):618-28. https:// doi.org/10.1016/j.tust.2007.11.005.

[22] Sun Y, Chen Y, Wang Z. Numerical simulation of inner support for excavation based on FEM software ABAQUS. Appl. Mech. Mater. 2012;236-237:632-5. https://doi.org/ 10.4028/www.scientific.net/AMM.236-237.632.

[23] Dassault Systèmes Simulia Corp. "Analysis User's Manual Volume 1: Introduction, Spatial modeling, execution and output. 6 Abaqus 2012;I:12.

[24] Sepehri M, Apel DB, Adeeb S, Leveille P, Hall RA. Evaluation of mining-induced energy and rockburst prediction at a diamond mine in Canada using a full 3D elastoplastic fi nite element model. Eng. Geol. February 2019;266:2020. https:// doi.org/10.1016/j.enggeo.2019.105457. 